This item was submitted to Loughborough's Research Repository by the author.

Items in Figshare are protected by copyright, with all rights reserved, unless otherwise indicated.

\title{
Effects of a self-managed home-based walking intervention on psychosocial health outcomes for breast cancer patients receiving chemotherapy: a randomised controlled trial
}

\section{PLEASE CITE THE PUBLISHED VERSION}

http://dx.doi.org/10.1007/s00520-015-2884-5

\section{PUBLISHER}

(C) Springer-Verlag

\section{VERSION}

AM (Accepted Manuscript)

\section{PUBLISHER STATEMENT}

This work is made available according to the conditions of the Creative Commons Attribution-NonCommercialNoDerivatives 4.0 International (CC BY-NC-ND 4.0) licence. Full details of this licence are available at: https://creativecommons.org/licenses/by-nc-nd/4.0/

\section{LICENCE}

CC BY-NC-ND 4.0

\section{REPOSITORY RECORD}

Gokal, Kajal, Deborah J. Wallis, Samreen Ahmed, Ion Boiangiu, Kiran Kancherla, and Fehmidah Munir. 2019. "Effects of a Self-managed Home-based Walking Intervention on Psychosocial Health Outcomes for Breast Cancer Patients Receiving Chemotherapy: A Randomised Controlled Trial". figshare.

https://hdl.handle.net/2134/19034. 
1 Effects of a self-managed home-based walking intervention on psychosocial health outcomes for

2 breast cancer patients receiving chemotherapy: a randomised controlled trial

3
Published in: Supportive Care Cancer, DOI 10.1007/s00520-015-2884-5

6 Kancherla ${ }^{3}$, Dr Fehmidah Munir 22015

${ }^{1}$ School of Sport, Exercise \& Health Sciences, Loughborough University, Loughborough, Leicestershire, LE11 3TU, UK.

92 National Centre for Sport and Exercise Medicine, Loughborough University, Loughborough, Leicestershire, LE11 3TU, UK

Statement to include: This activity was conducted under the auspices of the National Centre for 2 Sport and Exercise Medicine (NCSEM) England, a collaboration between several universities, NHS trusts and sporting and public bodies. The views expressed are those of the authors and not necessarily 4 those of NCSEM England or the partners involved.

${ }^{3}$ Leicester Royal Infirmary, Infirmary Square, Leicester, LE1 5WW, UK

${ }^{\S}$ Corresponding author.

Email addresses:

Kajal Gokal: k.gokal@lboro.ac.uk

Deborah Wallis: d.wallis@lboro.ac.uk

Samreen Ahmed: samreen.ahmed@uhl-tr.nhs.uk

Ion Boiangiu: ion.boiangiu@uhl-tr.nhs.uk

Kiran Kancherla: kiran.kancherla@uhl-tr.nhs.uk

Fehmidah Munir: f.munir@lboro.ac.uk

Competing Interests: The study is funded by Loughborough University as part of a PhD project.

Trial Registration: Current Controlled Trials ISRCTN50709297 


\section{Abstract:}

Purpose: To evaluate the effectiveness of a self-managed home-based moderate intensity walking intervention on psychosocial health outcomes among breast cancer patients undergoing chemotherapy.

Methods: The randomised controlled trial compared a self-managed, home-based walking intervention to usual care alone among breast cancer patients receiving chemotherapy. Outcome measures included changes in self-report measures of anxiety, depression, fatigue, self-esteem, mood and physical activity. Fifty participants were randomised to either the intervention group $(n=25)$, who received 12 weeks of moderate intensity walking, or the control group $(n=25)$ mid-way through chemotherapy. Participants in the intervention group were provided with a pedometer and were asked to set goals and keep weekly diaries outlining the duration, intensity and exertion of their walking. Levels of psychosocial functioning and physical activity were assessed pre and post intervention in both groups.

Results: The intervention had positive effects on fatigue $(F=5.77, p=0.02)$, self-esteem $(F=8.93$, $\mathrm{p}<0.001), \operatorname{mood}(F=4.73, p=0.03)$ and levels of physical activity $\left(x^{2}=17.15, \mathrm{p}=0.0011\right)$ but not anxiety $(F=0.90, p=0.35)$ and depression $(F=0.26, p=0.60)$ as assessed using the HADS. We found an $80 \%$ adherence rate to completing the 12 week intervention and recording weekly logs.

Conclusion: This self-managed, home-based intervention was beneficial for improving psychosocial well-being and levels of physical activity among breast cancer patients treated with chemotherapy.

Keywords: Breast cancer; Chemotherapy; Physical activity; Walking; Emotional distress; Psychosocial well-being. 
52 Fatigue, anxiety and depression are the most commonly reported psychosocial difficulties experienced by breast cancer patients. They can be evident for years after the completion of treatment [1] and can have a negative impact on the overall quality of life of breast cancer patients and survivors [2]. As these side effects are becoming more prominent and the number of patients surviving cancer is increasing, the focus of research has shifted towards improving the length of survival and quality of life [3].

A number of interventions including cognitive behavioural therapies, psycho-education, individual counselling, psychotherapy and social support $[4,5]$ have been introduced to help breast cancer patients manage symptoms associated with poor psychosocial well-being, such as anxiety, depression and quality of life. However, although the implementation of these interventions have demonstrated positive outcomes for addressing emotional distress experienced by patients, they fail to account for physical and functional difficulties encountered by patients, such as fatigue [6]. Physical activity addresses a broad range of health-related quality of life experienced by breast cancer patients $[7,8]$ and therefore may be a more effective intervention method. Participation in physical activity following a diagnosis of breast cancer has also been found to reduce the risk of cancer recurrence and improve the survival rates of cancer patients [9]. Physical activity such as walking, cycling, aerobics, resistance training, yoga and Qigong have shown positive effects in improving psychosocial health outcomes such as fatigue and depression in breast cancer patients [10] and survivors [11], particularly on the quality of life of breast cancer patients during active treatment $[12,13]$ and survivors posttreatment $[14,15]$. Participation in physical activity interventions has also been reported to reduce levels of fatigue $[3,7,16,17]$, anxiety $[18,19]$, and depression [20] and to improve self-esteem [16, $18]$ and levels of physical activity in patients $[16,18,21]$ and in survivors $[3,16,23]$. The evidence supporting the benefits of physical activity in breast cancer patients highlights the importance of encouraging patients to employ active lifestyles during treatment through to survivorship. 
Physical activity interventions have varied in duration from 4 weeks [24] to 6 months [25] and have been delivered in both individual [18] and group settings [13]. However, interventions that are delivered in group settings, or that are hospital-based and/or supervised, can restrict participation as patients undergoing chemotherapy are often busy with treatment schedules, are unwell or have limited access to exercise facilities due to transportation or scheduling difficulties [16]. To overcome such restrictions some researchers have moved towards the use of home-based, physical activity interventions for patients undergoing active treatment and report positive effects on psychosocial health outcomes $[21,25,26]$. However, some of these studies required regular facilitation by researchers or nursing staff. Although beneficial, such interventions are reported to be very time consuming for nurses and can also be expensive to run on a large scale. A number of interventions have assessed the effectiveness of self-managed interventions with cancer patients and produced promising results, particularly for home-based exercise programmes among cancer patients, in relation to increasing physical activity and in improving psychosocial health outcomes [27, 28]. A key strength of such interventions is that they are easily accessible and encourage patients to be more physically active during treatment with minimal input from healthcare professionals. Therefore selfmanaged interventions are low intensity and are more likely to sustain behaviour change when the intervention ends as it is not reliant on feedback from experts [28].

Home-based physical activity interventions have previously shown to improve psychosocial functioning in breast cancer patients $[21,25,29]$ and survivors $[16,22]$. However, these have been directed by researchers or nursing staff. Therefore, building on the need for more self-managed interventions, this study investigates the effectiveness of a 12 week self-managed, home-based walking intervention designed upon principles of The Theory of Planned Behaviour [30, 31]. The randomised controlled trial investigates the impact of walking on the psychosocial well-being of breast cancer patients receiving chemotherapy. The following hypotheses were tested: breast cancer patients who receive the walking intervention will report higher ratings of self-esteem, mood and physical activity and lower ratings of anxiety, depression and fatigue in comparison to the control group. 
104 Method

105 Design

106 The study compared 12 weeks of self-managed moderate intensity walking plus usual care $(n=25)$ to

107 usual care alone $(\mathrm{n}=25)$. Assessments were conducted pre-intervention and 12 weeks later at post-

108 intervention. Ethical approval for the study was obtained from the Loughborough University Ethical

109 Advisory Committee and the NHS Research Ethics Committee.

Recruitment

Participants were recruited from three outpatient clinics at the Leicester Royal Infirmary in the UK over a 16 month period. Patients with a diagnosis of breast cancer waiting to begin adjuvant or neoadjuvant chemotherapy and who were considered fit to take part in moderate intensity exercise by their oncologist, were invited to take part in the study. Women aged between 18 and 75 years were eligible for the study if they fulfilled the following criteria: a primary diagnosis of stage I to III breast cancer; waiting to begin chemotherapy; able to read and speak English; able to walk unassisted; and were relatively inactive ( $<30 \mathrm{~min}$ a day, 5 times a week of moderate intensity walking). Participants were excluded if they had prior history of cancer or if they had a current psychiatric illness that could hinder participation in the study procedures.

\section{Procedure}

Consenting participants were asked to complete all questionnaire measures of psychosocial health and subjective physical activity in the comfort of their own homes before beginning chemotherapy. Participants were asked to complete questionnaires a second time after they had completed 2 out of 6 cycles of chemotherapy (pre-intervention). Participants were then randomised into either the intervention or control group. Participants began the walking intervention after 2cycles of treatment as oncologists suggested that the intervention would be better received after patients had begun chemotherapy and understood what they were facing. Those who were randomised into the physical 
activity group were provided with intervention materials and those in the control group continued with usual care alone (medical care only)._All participants completed the questionnaires for the third time 12 weeks later (post-intervention), after the completion of six cycles of chemotherapy (see figure one).

\section{Intervention}

The intervention consisted of 12 weeks of home-based, self-managed, moderate intensity walking compared with usual care alone. Patients were provided with an intervention booklet including (see appendix) guidance and recommendations to ensure adherence to the intervention, tips and encouragement outlining the benefits of walking, and a diary to keep a log of walking duration and intensity. A number of physical activity interventions for cancer patients and cancer survivors have been developed and evaluated using tenets of the (TPB) and have found that those receiving the TPBbased interventions generally reported positive changes in their attitude toward, and participation in physical activity [30, 31].Therefore, this theory was used to design the self-management strategies in the home-based walking intervention booklet. A number of behavioural change techniques [32] based on the theory were incorporated as part of the intervention to help cancer patients plan their physical activity, set goals, self-monitor their progress and transform their intentions into actions [33].

Walking schedules were self-managed; however, the researcher recommended that participants began by completing 10 minutes of walking and then steadily increased the duration of walking to 30 minutes five times a week, in line with recommended guidelines [34].

The intervention booklet encouraged participants to make weekly goals outlining intended exercise intensity, duration and timing (exactly when they intend to exercise). The booklet encouraged reflection by asking participants to write down their achievements or shortfalls from previous weeks and to take these into consideration by modifying goals to ensure they were realistic and achievable. The booklet reminded participants to take their chemotherapy schedule into consideration when setting goals, and to self-check that they did not over exert themselves or set unrealistic goals during weeks in which they received treatment. Patients were also provided with the researcher's contact details if they had any questions regarding the intervention. 
The intervention group were provided with a Yamax Digi-Walker SW-200 pedometer for the duration of the intervention to measure daily step count and to provide immediate feedback and encourage motivation during the 12 week period. They were asked to keep a daily exercise diary outlining the number of steps taken, duration of walking bouts and perceived exertion rates. Those randomised to the control group received usual care alone.

\section{Measures}

Demographic, disease and treatment information was gathered via medical records and recruitment questionnaires. The following assessments were conducted at familiarisation, pre and post intervention.

Psychosocial measures (primary measures): Hospital Anxiety and Depression Scale (HADS) [35] is made up of two subscales, including 7 questions concerned with levels of anxiety and the remaining 7 with levels of depression. Physical and functional effects of fatigue were measured using The Functional Assessment of Cancer Therapy-Fatigue (FACT-F) [36]. The Self Esteem Scale (SES) [37] was used to measure positive and negative feelings about the self using a 10 item scale. The Profile of Mood States-Short Form (POMS-SF) [38] is a 37 item tool assessing transient, fluctuating and affective moods states and is made up of 6 subscales and has frequently been used in this population [39]. All measures are validated and have previously been used with breast cancer patients.

Physical Activity measures (secondary measures): Levels of perceived physical activity were measured using the General Practice Physical Activity Questionnaire [40]. Perceived exertion in the intervention group was monitored using the Borg Rating of Perceived Exertion Scale [41]. The Yamex Digi-walker SW-200 pedometer was worn by the intervention group and recorded the number of steps taken per day.

\section{Randomisation}

Block randomisation using four blocks was used to allocate patients into one of two groups by the researcher. Within each group of four patients, two were allocated to the intervention group and two 
to the control group; the allocation of groups within each block were random. This method was used in preference to simple random allocation to ensure equal numbers of consecutive patients in both groups, as recruitment was staggered [42].

\section{Sample size}

The study was designed to detect a standardised effect size of 0.5 [43] for repeated measures ANOVA with a power of 0.80 and $\alpha$ set at $5 \%$ significance level. Thus, 26 participants were required to complete each arm of the intervention.

\section{Statistical analysis}

All analyses were carried out using IBM SPSS version 21.0 for Windows. All between-group differences of categorical variables were analysed using Pearson's chi-square. Preliminary analyses compared baseline ratings of psychosocial health outcomes and perceived physical activity. Nonparametric tests were reported when Levene's $F$ test revealed that homogeneity of variance was violated.

To examine the difference in primary measures of psychosocial health outcomes between the intervention and the control group over time, a series of $2 \times 2$ mixed analyses of variance (ANOVAs) were conducted comparing baseline and post intervention data. Frequency analyses were conducted in order to determine differences between groups in self-reported physical activity using a series of Chisquare tests. Intention to treat (ITT) analysis was used as it includes all randomised patients in the groups to which they were randomly assigned regardless of subsequent withdrawal from treatment or deviation from the protocol. 


\section{Results}

212 Of the 96 eligible participants 33 (34\%) declined participation due to high levels of distress following

213

214

215

216

217

218

219

220

221

222

223 their diagnosis. In total 63 breast cancer patients due to begin adjuvant and neo adjuvant chemotherapy met the inclusion criteria, consented to take part and completed recruitment measures (recruitment rate of $69 \%$ ). A further 13 participants were lost to attrition due to changes in treatment after providing consent. Therefore 50 participants were randomised to the intervention $(n=25)$ or control group $(n=25)$.

\section{Sample characteristics}

As displayed in Table 1, the overall age of participants in the intervention group ranged from 27-74 years $($ mean $=52$ years; $\mathrm{SD}=11.7)$ and 29-66 years in the control group $($ mean $=52 ; \mathrm{SD}=8.9)$. There were no significant differences between groups in sociodemographic or treatment-related variables. Table 2 summarises demographic and cancer-related characteristics for participants who completed the study and those who withdrew following the familiarisation session. There was no significant difference in age between those who completed the study (mean $=52$ years; $\mathrm{SD}=10.29)$ and those who withdrew (mean $=55$ years; $\mathrm{SD}=12.67)$. Those who withdrew from the study had lower educational qualifications and were less likely to be in employment. Participants did not differ on any other demographic or cancer-related characteristics.

\section{Baseline characteristics}

Using ITT, there were no significant between group differences in baseline measures of anxiety, depression, fatigue, self-esteem, mood or subjective ratings of physical activity. There was a small difference between groups in two subscales of mood: vigour and confusion. At baseline, those randomised to the intervention group presented with higher scores of vigour and lower scores of confusion. However, these differences were controlled for using a mixed measures analyses. 
238 Adherence was calculated based upon the completion of the 12 week intervention. Twenty (80\%) out of the twenty-five participants randomised to the physical activity group adhered to the intervention and completed walking diaries. Five participants discontinued participation within the first few weeks of the 12 week intervention and did not complete the diaries. However, they completed all follow-up measures post-intervention. Using ITT analysis we included their data in the main analysis. Reasons for discontinuing participation in the intervention included hospitalisation and medical complications. Of the 20 participants that continued with the intervention, 16 completed walking diaries on a weekly basis and four participants had one or more weeks of missing diary data due to hospitalisation, but continued with the intervention after they were discharged and completed all other measures.

Effect of exercise intervention on psychosocial health outcomes

As seen in Table 3, significant time $\mathrm{x}$ group interactions revealed positive effects of the intervention on fatigue $F(1,48)=5.77 ; p=0.02$, self-esteem $F(1,48)=8.93 ; p=0.00$ and $\operatorname{mood} F(1,48)=$ $4.73 ; p=0.03$. Significant intervention effects were also revealed for three out of the six subscales assessing mood, including vigour $F(1,48)=11.23 ; p=0.00$, depression $F(1,48)=4.09 ; p=0.04$ and fatigue $F(1,48)=5.34 ; p=0.02$. Ratings of confusion and anger did not reach significance; however, positive trends towards the intervention were revealed. Anxiety and depression as measured by the HADS improved in both groups across the intervention period with no significant intervention effects.

Effect of exercise intervention on physical activity

Post-intervention analysis revealed significant differences between groups in perceived levels of physical activity, $x^{2}(3, \mathrm{~N}=50)=17.15, p=0.001$. When looking at groups individually, Table 4 illustrates that the majority of the intervention group (36\%) classed themselves as 'active' compared with no patients in the control group. Those who received the physical activity intervention altered their levels of physical activity from 'inactive' to 'active'. In contrast, over half (56\%) of the control group remained in the inactive group across the 12 week period. 
266 The aim of this study was to assess the effectiveness of a self-managed physical intervention in improving psychosocial health outcomes and levels of physical activity among breast cancer patients receiving chemotherapy. The 12 week intervention demonstrated significant positive effects on fatigue, self-esteem, overall mood and in three subscales of the POMS-SF: vigour, depression and fatigue. Conversely, no intervention effects were revealed for anxiety and depression as measured using the HADS or tension as measured using the POMS-SF. Overall, findings from the current study are encouraging and contribute new knowledge as they indicate that a self-managed, home-based physical activity intervention based upon the TPB can be successfully implemented to improve psychosocial health outcomes and physical activity among breast cancer patients actively receiving chemotherapy treatment. Furthermore, positive findings indicate the efficacy of self-managed interventions within this population without the need for individualised, supervised sessions which require specialist input, or additional support from healthcare professionals.

Our walking intervention increased self-reported physical activity levels which is promising as it demonstrates that a self-managed walking intervention can be successful without the need for additional

Increased levels of self-reported physical activity following our walking intervention are promising as they indicate positive effects of our self-managed intervention without the need for individualised sessions proposed in previous home-based interventions among breast cancer patients [21, 25] . Improving levels of physical activity in breast cancer patients has important implications for reducing risk of cancer reoccurrence and improving survival rate and mortality [9].

The self-managed intervention had a positive effect on fatigue and contributes to the evidence from previous physical activity interventions with breast cancer patients $[7,16,23,26]$. The intervention also provides further support for the benefits of physical activity for self-esteem in breast cancer patients [18]. Positive effects on self-esteem for an intervention that is implemented during chemotherapy is particularly interesting, as treatment for breast cancer can result in negative effects 
on body image and perceived femininity [44]. Therefore, a self-managed home-based walking intervention which can help to improve self-esteem during treatment should be encouraged and implemented on a larger scale. Positive effects of the intervention on self-esteem may also be due to the sense of achievement felt after setting and achieving self-prescribed walking goals. Further research and/or interventions are required to test this possibility.

A significant intervention effect was revealed on total mood disturbance in line with previous homebased physical activity interventions $[16,26]$. These findings are of particular interest as they demonstrate the benefits of the physical activity intervention on mood without the need for additional counselling or social support from either a nurse or through cancer group based support. Interestingly, anger increased in our control group and decreased in our intervention group across the 12 week intervention period. Although results did not reach significance, these results are important as they suggest that self-managed physical activity might help to improve feelings of anger in breast cancer patients during chemotherapy. Similarly, intervention effects on improving feelings of confusion were promising but did not reach significance.

The intervention had no significant effects on anxiety and depression as measured by the HADS or tension as measured by the POMS-SF. It should be noted, however, that all three constructs improved in both groups across the 12 week period from mid-chemotherapy to post-chemotherapy. These results, therefore, suggest that these aspects of psychosocial health may improve naturally over time. There is some evidence on depression to support this whereby levels of depression have been found to decrease naturally over time in cancer patients [45].

Strengths of our study include the direct comparison of walking to usual care alone in a homogenous sample of breast cancer patients undergoing chemotherapy. The success of the intervention designed using the principles of TPB, the use of ITT analyses and validated measures of psychosocial functioning also add to the strength of our study. In addition, both groups received the same level of researcher attention, confirming that improvements in psychosocial outcome in our treatment group were the result of the intervention as opposed to increased attention. 
317 Key strengths of our study include the self-managed, home-based nature of the walking intervention

318 along with its low cost design, which requires no face-to-face contact, guidance throughout the

319 intervention or any exercise equipment. Furthermore, unlike previous home-based interventions, the

320 current study did not require additional telephone contact or counselling with health care professionals

321 and required no additional burden upon staff. Therefore, the current intervention makes a promising

322 contribution to current literature and has important implications for the development of self-managed

323 interventions that can benefit a large number of cancer patients.

324 Limitations include the relatively small sample size and the lack of generalizability, as participants were all recruited from the same centre. Furthermore, the exclusion of participants who were unable to speak and read English resulted in eliminating participants from diverse ethnic backgrounds. The lack of follow-up measures after completion of the intervention and treatment (e.g. three months postintervention) is a limitation of the current study. Future intervention studies should include assessment of psychosocial health outcomes at three to six months post-intervention in order to investigate if benefits of exercise are short term or if there are additional long term benefits. Follow-up assessments would also allow researchers to see if participants continue with the walking post-intervention and adapt exercise into their daily routines or if they revert back to being sedentary.

In summary, this randomised controlled trial was successful in providing health care professionals with an efficient, self-managed intervention to improve fatigue, mood and self-esteem and the overall quality of life of breast cancer patients actively undergoing chemotherapy. Providing patients with the ability to self-manage their own exercise schedules is less onerous on oncology staff and nurses and therefore can be introduced on a large scale. Furthermore, our intervention results indicate that a home-based, self-managed, moderate intensity intervention can successfully be incorporated around treatment schedules for breast cancer patients undergoing treatment. However, further intervention research with a large sample size and with other types of cancer patients is planned to confirm preliminary findings. 


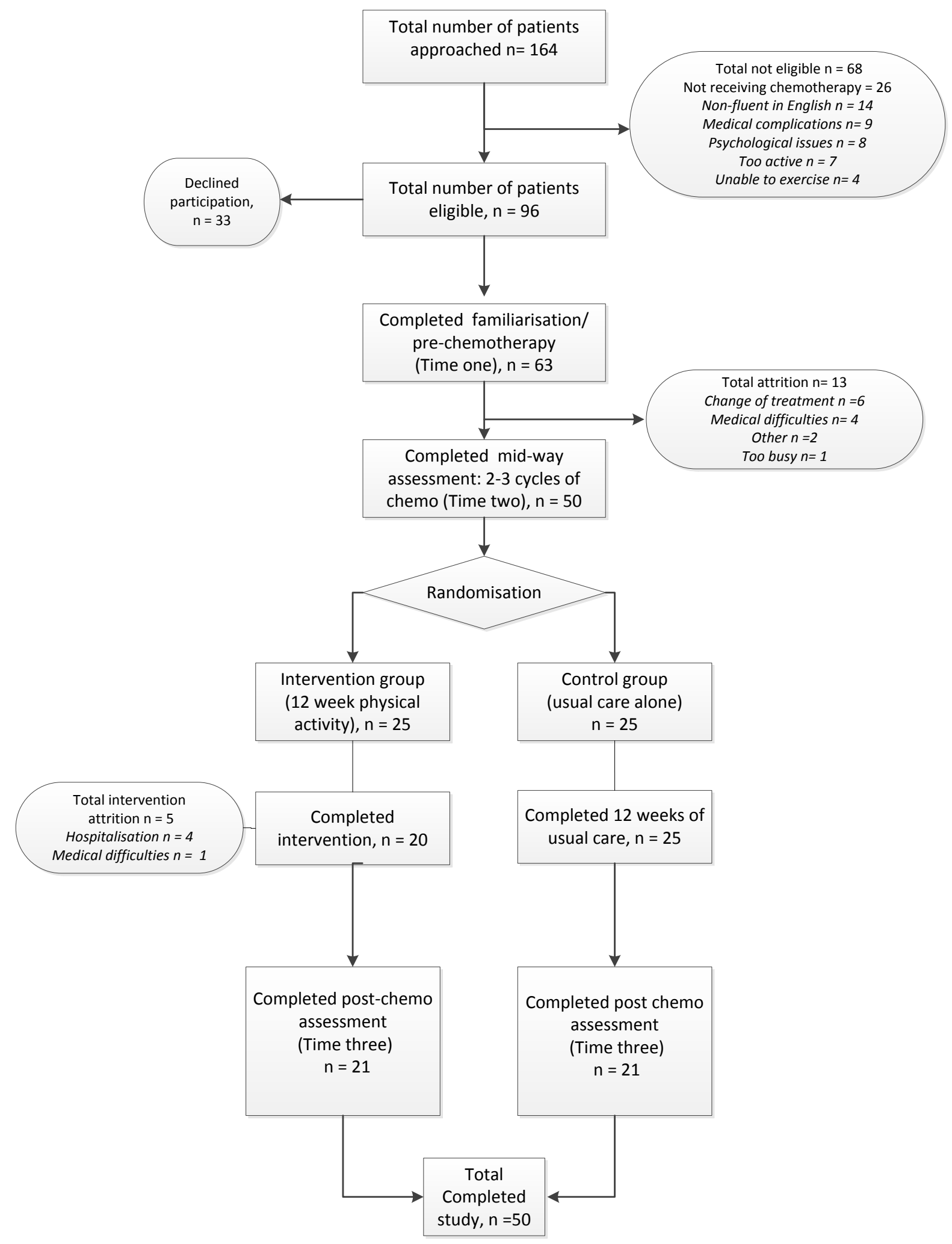

343 Figure 1: Study recruitment and attrition rates 
Table 1: Demographic and treatment characteristics for intervention and control group

\begin{tabular}{|c|c|c|c|c|c|}
\hline Characteristic & \multicolumn{2}{|c|}{ Intervention $(\mathrm{n}=\mathbf{2 5})$} & \multicolumn{2}{|c|}{ Control $(n=25)$} & \multirow[b]{2}{*}{$\mathrm{p}=.500$} \\
\hline $\begin{array}{ll}\text { Age (years) } & M(\mathrm{SD})\end{array}$ & 52.08 & $(11.7)$ & 52.36 & $(8.9)$ & \\
\hline$M(S D)$ & 27.20 & $(4.82)$ & 28.25 & $(5.83)$ & $\mathrm{p}=.501$ \\
\hline & $N$ & $\%$ & $N$ & $\%$ & $x^{2}$ \\
\hline \multicolumn{6}{|l|}{ Education } \\
\hline None & 3 & 12 & 6 & 24 & \\
\hline GCSE (or equivalent) & 11 & 44 & 9 & 36 & \\
\hline A level (or equivalent) & 3 & 12 & 7 & 28 & \\
\hline Degree & 5 & 20 & 2 & 8 & \\
\hline Higher Degree & 3 & 12 & 1 & 4 & \\
\hline \multicolumn{6}{|l|}{ Marital status } \\
\hline Single & 2 & 8 & 3 & 12 & \\
\hline $\begin{array}{l}\text { Married/living with } \\
\text { partner }\end{array}$ & 19 & 76 & 19 & 76 & \\
\hline Separated/divorced & 3 & 12 & 2 & 8 & \\
\hline Widowed & 1 & 4 & 1 & 4 & .940 \\
\hline \multicolumn{6}{|l|}{ Employment status } \\
\hline Working & 5 & 20 & 5 & 20 & \\
\hline Sick leave & 17 & 68 & 16 & 64 & \\
\hline Retired & 3 & 12 & 4 & 16 & \\
\hline \multirow{2}{*}{\multicolumn{6}{|c|}{ Breast cancer type }} \\
\hline & & & & & \\
\hline Invasive lobular & $\begin{array}{c}24 \\
1\end{array}$ & $\begin{array}{c}90 \\
4\end{array}$ & $\begin{array}{c}23 \\
2\end{array}$ & $\begin{array}{c}92 \\
8\end{array}$ & .552 \\
\hline \multicolumn{6}{|l|}{ Cancer grade } \\
\hline I & 0 & 0 & 1 & 4 & \\
\hline II & 5 & 20 & 8 & 32 & \\
\hline III & 20 & 80 & 16 & 64 & .344 \\
\hline \multicolumn{6}{|l|}{ Chemotherapy type } \\
\hline FEC & 12 & 48 & 9 & 36 & \\
\hline FEC-T & 13 & 52 & 16 & 64 & \\
\hline \multicolumn{5}{|l|}{ Treatment type } & .390 \\
\hline Adjuvant & 20 & 80 & 21 & 84 & \\
\hline \multirow[t]{2}{*}{ Neo-adjuvant } & 5 & 20 & 4 & 16 & \\
\hline \multirow{2}{*}{\multicolumn{6}{|c|}{ Surgery type }} \\
\hline & & & & & \\
\hline Lumpectomy & 17 & 68 & 15 & 60 & \\
\hline Mastectomy & 7 & 28 & 10 & 40 & \\
\hline Segmental & 1 & 4 & 0 & 0 & .437 \\
\hline
\end{tabular}


Menopausal status

Pre-menopausal

$12 \quad 48$

48

$\begin{array}{llll}13 & 52 & 18 & 72\end{array}$

7

28

.150

Self-report physical

activity

Inactive

$\begin{array}{llll}16 & 64 & 15 & 60\end{array}$

Moderately inactive

Moderately active

$4 \quad 16$

$4 \quad 16$

Active

20

$\begin{array}{cccc}5 & 20 & 6 & 24 \\ 0 & 0 & 0 & 0\end{array}$
.940

347 Note. FEC (fluorouracil, epirubicin and cyclophosphamide); FET-T (FEC followed by taxotere). 
351 Table 2: Demographic and treatment characteristics for completed and withdrawn participants

\begin{tabular}{|c|c|c|c|c|c|c|}
\hline & cteristic & \multicolumn{2}{|c|}{ Completed $(n=50)$} & \multicolumn{2}{|c|}{ Withdrawn $(n=13)$} & \\
\hline Age & $\mathrm{M}(\mathrm{SD})$ & 52 & (10.29) & 55 & (12.67) & $\mathrm{p}=.399$ \\
\hline BMI & $\mathrm{M}(\mathrm{SD})$ & 27.72 & $(5.14)$ & 28.96 & $(4.07)$ & $\mathrm{p}=.427$ \\
\hline
\end{tabular}

\section{Education}

None

$\begin{array}{llll}9 & 18 & 5 & 38\end{array}$

GCSE (or equivalent)

A level (or equivalent)

Degree

Higher Degree

$20 \quad 40$

$10 \quad 20$

$7 \quad 14$

8

4

23

(1)

8

.000

Marital status

Single

Married/living with

5

partner

Separated/divorced

Widowed

10

76

7

69

$5 \quad 10$

2

15

Employment status

Working

Sick leave

10

Retired

Breast cancer type

Invasive ductal

Invasive lobular

\section{Cancer grade}

I
II
III

Chemotherapy type

FEC

FEC-T

Treatment type

Adjuvant

$$
82
$$

18

Surgery type

Lumpectomy

Mastectomy

Segmental

32

\section{Menopausal Status}

Pre-menopausal

Post-menopausal

19

31

32

62

64

34

2

77

15

8

Self-report physical activity

Inactive

Moderately inactive

Moderately active

Active

$\begin{array}{cccc}31 & 62 & 12 & 92 \\ 8 & 16 & 1 & 7 \\ 11 & 22 & 0 & 0 \\ 0 & 0 & 0 & 0\end{array}$

30

69

.630 
Table 3: Independent t-tests for intervention group $(\mathrm{n}=25)$ and control group $(\mathrm{n}=25)$ at pre-intervention (preliminary results), post-intervention and mixed measures ANOVA between time and group

\begin{tabular}{|c|c|c|c|c|c|c|c|c|}
\hline \multirow[t]{2}{*}{ Variable } & \multicolumn{2}{|c|}{ Pre-intervention } & & \multicolumn{2}{|c|}{ Post-intervention } & \multirow[t]{2}{*}{ Group } & \multirow[t]{2}{*}{ Time } & \multirow[t]{2}{*}{ Time x Group } \\
\hline & $\begin{array}{c}\text { Intervention } \\
M(S D)\end{array}$ & $\begin{array}{c}\text { Control } \\
M(S D)\end{array}$ & $p$ & $\begin{array}{c}\text { Intervention } \\
M(S D)\end{array}$ & $\begin{array}{c}\text { Control } \\
M(S D)\end{array}$ & & & \\
\hline $\begin{array}{l}\text { HADS } \\
\text { Anxiety }\end{array}$ & $4.40(2.79)$ & $5.28(3.54)$ & 0.33 & $2.12(1.83)$ & $3.80(3.23)$ & $\begin{array}{l}F=3.70 \\
p=0.06\end{array}$ & $\begin{array}{c}F=15.90 \\
\mathbf{p}=\mathbf{0 . 0 0}\end{array}$ & $\begin{array}{l}F=0.90 \\
p=0.35\end{array}$ \\
\hline Depression & $5.52(3.79)$ & $6.68(4.00)$ & 0.30 & $4.44(3.37)$ & $6.16(2.21)$ & $\begin{array}{l}F=3.23 \\
p 0.79\end{array}$ & $\begin{array}{l}F=2.17 \\
p=0.14\end{array}$ & $\begin{array}{l}F=0.26 \\
p=0.60\end{array}$ \\
\hline $\begin{array}{l}\text { POMS-SF } \\
\text { Tension }\end{array}$ & $6.08(4.14)$ & $8.60(6.22)$ & $0.09^{9}$ & $3.00(3.76)$ & $6.80(4.37)$ & $\begin{array}{l}F=7.60 \\
\mathbf{p}=\mathbf{0 . 0 0}\end{array}$ & $\begin{array}{c}F=12.62 \\
\mathbf{p}=\mathbf{0 . 0 0}\end{array}$ & $\begin{array}{l}F=0.86 \\
p=0.35\end{array}$ \\
\hline Vigour & $10.56(4.77)$ & $7.92(3.82)$ & $0.04 *$ & $14.04(3.70)$ & $7.52(4.36)$ & $\begin{array}{r}F=19.61 \\
\mathbf{p}=\mathbf{0 . 0 0}\end{array}$ & $\begin{array}{l}F=7.07 \\
\mathbf{p}=\mathbf{0 . 0 1}\end{array}$ & $\begin{array}{c}F=11.23 \\
\mathbf{p}=\mathbf{0 . 0 0}\end{array}$ \\
\hline Depression & $4.92(5.31)$ & $6.68(5.72)$ & 0.27 & $1.68(2.01)$ & $6.44(4.99)$ & $\begin{array}{l}F=8.50 \\
\mathbf{p}=\mathbf{0 . 0 0}\end{array}$ & $\begin{array}{l}F=5.50 \\
\mathbf{p}=\mathbf{0 . 0 2}\end{array}$ & $\begin{array}{l}F=4.09 \\
\mathbf{p}=\mathbf{0 . 0 4}\end{array}$ \\
\hline Fatigue & $8.28(5.46)$ & $10.00(5.71)$ & 0.28 & $4.20(3.35)$ & $9.24(4.73)$ & $\begin{array}{l}F=8.11 \\
\mathbf{p}=\mathbf{0 . 0 0}\end{array}$ & $\begin{array}{c}F=11.35 \\
\mathbf{p}=\mathbf{0 . 0 0}\end{array}$ & $\begin{array}{l}F=5.34 \\
\mathbf{p}=\mathbf{0 . 0 2}\end{array}$ \\
\hline Anger & $2.68(2.23)$ & $3.92(3.95)$ & $0.20^{\mathrm{a}}$ & $2.00(2.79)$ & $4.92(3.96)$ & $\begin{array}{l}F=6.87 \\
\mathbf{p}=\mathbf{0 . 0 1}\end{array}$ & $\begin{array}{l}F=0.10 \\
p=0.75\end{array}$ & $\begin{array}{l}F=2.77 \\
p=0.10\end{array}$ \\
\hline Confusion & $2.68(2.23)$ & $5.76(4.18)$ & 0.02 * & $1.84(1.37)$ & $5.52(3.69)$ & $\begin{array}{c}F=15.43 \\
\mathbf{p}=\mathbf{0 . 0 0}\end{array}$ & $\begin{array}{l}F=5.09 \\
\mathbf{p}=\mathbf{0 . 0 2}\end{array}$ & $\begin{array}{l}F=2.86 \\
p=0.09\end{array}$ \\
\hline Total Mood & $15.88(21.22)$ & $28.32(26.86)$ & 0.08 & $4.20(14.67)$ & $27.76(21.35)$ & $\begin{array}{r}F=10.67 \\
\mathbf{p}=\mathbf{0 . 0 0}\end{array}$ & $\begin{array}{l}F=5.73 \\
\mathbf{p}=\mathbf{0 . 0 2}\end{array}$ & $\begin{array}{l}F=4.73 \\
\mathbf{p}=\mathbf{0 . 0 3}\end{array}$ \\
\hline $\begin{array}{l}\text { FACT-F } \\
\text { Fatigue }\end{array}$ & $32.16(8.42)$ & $34.24(9.48)$ & 0.41 & $26.04(3.80)$ & $33.60(7.29)$ & $\begin{array}{l}F=7.10 \\
\mathbf{p}=\mathbf{0 . 0 1}\end{array}$ & $\begin{array}{l}F=8.78 \\
\mathbf{p}=\mathbf{0 . 0 0}\end{array}$ & $\begin{array}{l}F=5.77 \\
\mathbf{p}=\mathbf{0 . 0 2}\end{array}$ \\
\hline $\begin{array}{l}\text { SES } \\
\text { Self-esteem }\end{array}$ & $21.68(4.43)$ & $20.44(4.94)$ & 0.62 & $23.80(4.59)$ & $19.52(4.18)$ & $\begin{array}{l}F=8.93 \\
\mathbf{p}=\mathbf{0 . 0 0}\end{array}$ & $\begin{array}{l}F=1.39 \\
p=0.24\end{array}$ & $\begin{array}{l}F=8.93 \\
\mathbf{p}=\mathbf{0 . 0 0}\end{array}$ \\
\hline
\end{tabular}

HADS, Hospital Anxiety and Depression Scale, POMS-SF Profile of Mood States-Short Form, FACT-F The Functional Assessment of Cancer therapy-Fatigue,

SES Rosenberg Self-esteem Scale, M, Mean, SD, standard deviation; ${ }^{*} \mathrm{p}<0.05 ;{ }^{* *} \mathrm{p}<0.01 .{ }^{a}$ Mann Whitney U (assumption of homogeneity of variance violated) 
Table 4: Chi-square analysis between intervention $(n=25)$ and control group $(n=25)$ at pre and post-intervention.

\begin{tabular}{|c|c|c|c|c|c|c|c|c|c|c|}
\hline \multirow[t]{3}{*}{ Variable } & \multicolumn{5}{|c|}{$\begin{array}{c}\text { Time one } \\
\text { (pre-intervention) }\end{array}$} & \multicolumn{5}{|c|}{$\begin{array}{c}\text { Time two } \\
\text { (post-intervention) }\end{array}$} \\
\hline & \multicolumn{2}{|c|}{$\begin{array}{l}\text { Intervention } \\
\quad(\mathrm{n}=25)\end{array}$} & \multicolumn{2}{|c|}{$\begin{array}{l}\text { Control } \\
(\mathrm{n}=25)\end{array}$} & \multirow{2}{*}{$\begin{array}{c}\text { Result } \\
x^{2}\end{array}$} & \multicolumn{2}{|c|}{$\begin{array}{c}\text { Intervention } \\
(\mathrm{n}=25)\end{array}$} & \multicolumn{2}{|c|}{$\begin{array}{l}\text { Control } \\
(\mathrm{n}=25)\end{array}$} & \multirow{2}{*}{$\begin{array}{c}\text { Result } \\
x^{2}\end{array}$} \\
\hline & $N$ & $\%$ & $N$ & $\%$ & & $N$ & $\%$ & $N$ & $\%$ & \\
\hline \multicolumn{11}{|l|}{$\begin{array}{l}\text { Perceived physical } \\
\text { activity }\end{array}$} \\
\hline Inactive & 16 & 64 & 15 & 60 & & 4 & 16 & 14 & 56 & \\
\hline Moderately inactive & 4 & 16 & 4 & 16 & & 6 & 24 & 9 & 36 & \\
\hline Moderately active & 5 & 20 & 6 & 24 & & 6 & 24 & 2 & 8 & \\
\hline \multirow[t]{2}{*}{ Active } & 0 & 0 & 0 & 0 & & 9 & 36 & 0 & 0 & \\
\hline & & & & & .940 & & & & & .001 \\
\hline
\end{tabular}




\section{Acknowledgements}

We would like to thank all participants who have agreed to take part in the clinical trial and have given us their time and input into the study.

\section{Conflict of Interest}

There are no conflicts of interest to report and we certify that the article is original work.

\section{References}

[1] W. K. W. So, G. Marsh, W. M. Ling, F. Y. Leung, J. C. K. Lo, M. Yeung, and G. K. H. Li, "The symptom cluster of fatigue, pain, anxiety, and depression and the effect on the quality of life of women receiving treatment for breast cancer: a multicenter study.," Oncol. Nurs. Forum, vol. 36, no. 4, pp. E205-14, Jul. 2009.

[2] H. M. Penttinen, T. Saarto, P. Kellokumpu-Lehtinen, C. Blomqvist, R. Huovinen, H. Kautiainen, S. Järvenpää, R. Nikander, I. Idman, R. Luoto, H. Sievänen, M. Utriainen, L. Vehmanen, A. S. Jääskeläinen, A. Elme, J. Ruohola, M. Luoma, and L. Hakamies-Blomqvist, "Quality of life and physical performance and activity of breast cancer patients after adjuvant treatments.," Psychooncology., vol. 20, no. 11, pp. 1211-20, Nov. 2011.

[3] S. C. Hayes, S. Rye, T. Disipio, P. Yates, J. Bashford, C. Pyke, C. Saunders, D. Battistutta, and E. Eakin, "Exercise for health: a randomized, controlled trial evaluating the impact of a pragmatic, translational exercise intervention on the quality of life, function and treatment-related side effects following breast cancer.," Breast Cancer Res. Treat., vol. 137, no. 1, pp. 175-86, Jan. 2013.

[4] A. C. Marcus, K. M. Garrett, D. Cella, L. Wenzel, M. J. Brady, D. Fairclough, M. Pate-Willig, D. Barnes, S. P. Emsbo, B. C. Kluhsman, L. Crane, S. Sedlacek, and P. J. Flynn, "Can telephone counseling post-treatment improve psychosocial outcomes among early stage breast cancer survivors?," Psychooncology., vol. 19, no. 9, pp. 923-32, Sep. 2010.

[5] S. Dolbeault, S. Cayrou, A. Brédart, A. L. Viala, B. Desclaux, P. Saltel, A. Gauvain-Piquard, P. Hardy, and P. Dickes, "The effectiveness of a psychoeducational group after early-stage breast cancer treatment: results of a randomized French study.," Psychooncology., vol. 18, no. 6, pp. 647-56, Jun. 2009.

[6] M. C. Wilmoth, E. A. Coleman, S. C. Smith, and C. Davis, "Fatigue, weight gain, and altered sexuality in patients with breast cancer: exploration of a symptom cluster.," Oncol. Nurs. Forum, vol. 31, no. 6, pp. 1069-75, Nov. 2004.

[7] C. L. Battaglini, J. P. Mihalik, M. Bottaro, C. Dennehy, M. A. Petschauer, L. S. Hairston, and E. W. Shields, "Effect of exercise on the caloric intake of breast 
cancer patients undergoing treatment.," Braz. J. Med. Biol. Res., vol. 41, no. 8, pp. 709-15, Aug. 2008.

[8] K. S. Courneya and C. M. Friedenreich, "Relationship Between Exercise Pattern Across the Cancer Experience and Current Quality of Life in Colorectal Cancer Survivors," J. Altern. Complement. Med., vol. 3, no. 3, pp. 215-226, Sep. 1997.

[9] N. J. Davies, L. Batehup, and R. Thomas, "The role of diet and physical activity in breast, colorectal, and prostate cancer survivorship: a review of the literature.," Br. J. Cancer, vol. 105 Suppl , pp. S52-73, Nov. 2011.

[10] S. I. Mishra, R. W. Scherer, C. Snyder, P. M. Geigle, D. R. Berlanstein, and O. Topaloglu, "Exercise interventions on health-related quality of life for people with cancer during active treatment.," Cochrane database Syst. Rev., vol. 8, p. CD008465, Jan. 2012.

[11] S. I. Mishra, R. W. Scherer, P. M. Geigle, D. R. Berlanstein, O. Topaloglu, C. C. Gotay, and C. Snyder, "Exercise interventions on health-related quality of life for cancer survivors.," Cochrane database Syst. Rev., vol. 8, p. CD007566, Jan. 2012.

[12] T. DiSipio, S. Rye, M. Newton, L. Guy, K. Spathonis, E. Eakin, and S. Hayes, "Exercise for health : a breast cancer recovery program - quality of life benefits [Conference Abstract]," Asia Pacific Journal of Clinical Oncology [Special Issue: Abstracts of the 36th Annual Scientific Meeting, Clinical Oncological Society of Australia]. Wiley-Blackwell Publishing Ltd., 17-Nov-2009.

[13] N. Mutrie, A. M. Campbell, F. Whyte, A. McConnachie, C. Emslie, L. Lee, N. Kearney, A. Walker, and D. Ritchie, "Benefits of supervised group exercise programme for women being treated for early stage breast cancer: pragmatic randomised controlled trial.," BMJ, vol. 334, no. 7592, p. 517, Mar. 2007.

[14] O.-H. Cho, Y.-S. Yoo, and N.-C. Kim, "Efficacy of comprehensive group rehabilitation for women with early breast cancer in South Korea.," Nurs. Health Sci., vol. 8, no. 3, pp. 140-6, Sep. 2006.

[15] S. L. Sandel, J. O. Judge, N. Landry, L. Faria, R. Ouellette, and M. Majczak, "Dance and movement program improves quality-of-life measures in breast cancer survivors.," Cancer Nurs., vol. 28, no. 4, pp. 301-9, 2005.

[16] B. M. Pinto, G. M. Frierson, C. Rabin, J. J. Trunzo, and B. H. Marcus, "Homebased physical activity intervention for breast cancer patients.," J. Clin. Oncol., vol. 23, no. 15, pp. 3577-87, May 2005. 
[17] J. K. H. Vallance, K. S. Courneya, R. C. Plotnikoff, Y. Yasui, and J. R. Mackey, "Randomized controlled trial of the effects of print materials and step pedometers on physical activity and quality of life in breast cancer survivors.," $J$. Clin. Oncol., vol. 25, no. 17, pp. 2352-9, Jun. 2007.

[18] K. S. Courneya, R. J. Segal, K. Gelmon, R. D. Reid, J. R. Mackey, C. M. Friedenreich, C. Proulx, K. Lane, A. B. Ladha, J. K. Vallance, Q. Liu, Y. Yasui, and D. C. McKenzie, "Six-month follow-up of patient-rated outcomes in a randomized controlled trial of exercise training during breast cancer chemotherapy.," Cancer Epidemiol. Biomarkers Prev., vol. 16, no. 12, pp. 25728, Dec. 2007.

[19] H. S. Vadiraja, R. M. Raghavendra, R. Nagarathna, H. R. Nagendra, M. Rekha, N. Vanitha, K. S. Gopinath, B. S. Srinath, M. S. Vishweshwara, Y. S. Madhavi, B. S. Ajaikumar, B. S. Ramesh, R. Nalini, and V. Kumar, "Effects of a yoga program on cortisol rhythm and mood states in early breast cancer patients undergoing adjuvant radiotherapy: a randomized controlled trial.," Integr. Cancer Ther., vol. 8, no. 1, pp. 37-46, Mar. 2009.

[20] A. Mehnert, S. Veers, D. Howaldt, K.-M. Braumann, U. Koch, and K.-H. Schulz, "Effects of a physical exercise rehabilitation group program on anxiety, depression, body image, and health-related quality of life among breast cancer patients.," Onkologie, vol. 34, no. 5, pp. 248-53, Jan. 2011.

[21] M. Backman, Y. Wengström, B. Johansson, I. Sköldengen, S. Börjesson, S. Tärnbro, and $\AA$. Berglund, "A randomized pilot study with daily walking during adjuvant chemotherapy for patients with breast and colorectal cancer.," Acta Oncol., vol. 53, no. 4, pp. 510-20, Apr. 2014.

[22] L. Q. Rogers, P. Hopkins-Price, S. Vicari, R. Pamenter, K. S. Courneya, S. Markwell, S. Verhulst, K. Hoelzer, C. Naritoku, L. Jones, G. Dunnington, V. Lanzotti, J. Wynstra, L. Shah, B. Edson, A. Graff, and M. Lowy, "A randomized trial to increase physical activity in breast cancer survivors.," Med. Sci. Sports Exerc., vol. 41, no. 4, pp. 935-46, Apr. 2009.

[23] L. Fillion, P. Gagnon, F. Leblond, C. Gélinas, J. Savard, R. Dupuis, K. Duval, and M. Larochelle, "A brief intervention for fatigue management in breast cancer survivors.," Cancer Nurs., vol. 31, no. 2, pp. 145-59, Jan. 2008.

[24] L. A. Cadmus, P. Salovey, H. Yu, G. Chung, S. Kasl, and M. L. Irwin, "Exercise and quality of life during and after treatment for breast cancer: results of two randomized controlled trials.," Psychooncology., vol. 18, no. 4, pp. 343-52, Apr. 2009. 
[25] A. M. L. Husebø, S. M. Dyrstad, I. Mjaaland, J. A. Søreide, and E. Bru, "Effects of scheduled exercise on cancer-related fatigue in women with early breast cancer.," ScientificWorldJournal., vol. 2014, p. 271828, Jan. 2014.

[26] C.Y. Yang, J.-C. Tsai, Y.-C. Huang, and C.-C. Lin, "Effects of a home-based walking program on perceived symptom and mood status in postoperative breast cancer women receiving adjuvant chemotherapy.," J. Adv. Nurs., vol. 67, no. 1, pp. 158-68, Jan. 2010.

[27] E. Jeffs and T. Wiseman, "Randomised controlled trial to determine the benefit of daily home-based exercise in addition to self-care in the management of breast cancer-related lymphoedema: a feasibility study.," Support. Care Cancer, vol. 21, no. 4, pp. 1013-23, Apr. 2013.

[28] M. K. Lee, Y. H. Yun, H.-A. Park, E. S. Lee, K. H. Jung, and D.-Y. Noh, “A Web-based self-management exercise and diet intervention for breast cancer survivors: pilot randomized controlled trial.," Int. J. Nurs. Stud., vol. 51, no. 12, pp. 1557-67, Dec. 2014.

[29] V. Mock, M. Pickett, M. E. Ropka, E. Muscari Lin, K. J. Stewart, V. A. Rhodes, R. McDaniel, P. M. Grimm, S. Krumm, and R. McCorkle, "Fatigue and quality of life outcomes of exercise during cancer treatment.," Cancer Pract., vol. 9, no. 3, pp. 119-27, 2001.

[30] F. G. Stacey, E. L. James, K. Chapman, K. S. Courneya, and D. R. Lubans, “A systematic review and meta-analysis of social cognitive theory-based physical activity and/or nutrition behavior change interventions for cancer survivors.," $J$. Cancer Surviv., Nov. 2014.

[31] E. K. Olander, H. Fletcher, S. Williams, L. Atkinson, A. Turner, and D. P. French, "What are the most effective techniques in changing obese individuals' physical activity self-efficacy and behaviour: a systematic review and metaanalysis.," Int. J. Behav. Nutr. Phys. Act., vol. 10, no. 1, p. 29, Jan. 2013.

[32] S. Michie, M. Richardson, M. Johnston, C. Abraham, J. Francis, W. Hardeman, M. P. Eccles, J. Cane, and C. E. Wood, "The behavior change technique taxonomy (v1) of 93 hierarchically clustered techniques: building an international consensus for the reporting of behavior change interventions.," Ann. Behav. Med., vol. 46, no. 1, pp. 81-95, Aug. 2013.

[33] P. M. Gollwitzer, "Implementation intentions: Strong effects of simple plans.," Am. Psychol., vol. 54, no. 7, pp. 493-503, 1999. 
[34] Department of Health, Physical Activity, Health Improvement and Prevention (2004). At least five a week.

http://www.image.guardian.co.uk/sysfiles/Society/.../04/.../At_least5aweek.pdf.

[35] A. S. Zigmond and R. P. Snaith, "The hospital anxiety and depression scale.," Acta Psychiatr. Scand., vol. 67, no. 6, pp. 361-70, Jun. 1983.

[36] S. B. Yellen, D. F. Cella, K. Webster, C. Blendowski, and E. Kaplan, "Measuring fatigue and other anemia-related symptoms with the Functional Assessment of Cancer Therapy (FACT) measurement system," J. Pain Symptom Manage., vol. 13, no. 2, pp. 63-74, Feb. 1997.

[37] M. Rosenberg, "Rosenberg self-esteem scale (RSE)," Accept. Commit. Ther., p. $61,1965$.

[38] S. Shacham, "A shortened version of the Profile of Mood States.," J. Pers. Assess., vol. 47, no. 3, pp. 305-6, Jun. 1983.

[39] T. A. Dilorenzo, D. H. Bovbjerg, G. H. Montgomery, H. Valdimarsdottir, and P. B. Jacobsen, "The application of a shortened version of the profile of mood states in a sample of breast cancer chemotherapy patients," Br. J. Health Psychol., vol. 4, no. 4, pp. 315-325, Nov. 1999.

[40] Department. of Health, "The General Practice Physical Activity Questionnaire (GPPAQ).” https://www.gov.uk/government/publications/general-practicephysical-activity-questionnaire-gppaq

[41] G. Borg, Borg's perceived exertion and pain scales. 1998.

[42] D. G. Altman and J. M. Bland, "Statistics notes: How to randomise," BMJ, vol. 319, no. 7211, pp. 703-704, Sep. 1999.

[43] J. Cohen, “A power primer.," Psychol. Bull., vol. 112, no. 1, pp. 155-9, Jul. 1992.

[44] C. Berterö and M. Chamberlain Wilmoth, "Breast cancer diagnosis and its treatment affecting the self: a meta-synthesis.," Cancer Nurs., vol. 30, no. 3, pp. 194-202; quiz 203-4, 2007.

[45] J. H. Park, E. Y. Jun, M. Y. Kang, Y. S. Joung, and G. S. Kim, "[Symptom experience and quality of life in breast cancer survivors].," J. Korean Acad. Nurs., vol. 39, no. 5, pp. 613-21, Oct. 2009. 
Appendix: Intervention booklet

\section{Step up, take control \& walk towards wellness}

LOUGHBOROUGH UNIVERSITY RESEARCH TEAM

K.GOKAL, F.MUNIR, D.WALLIS

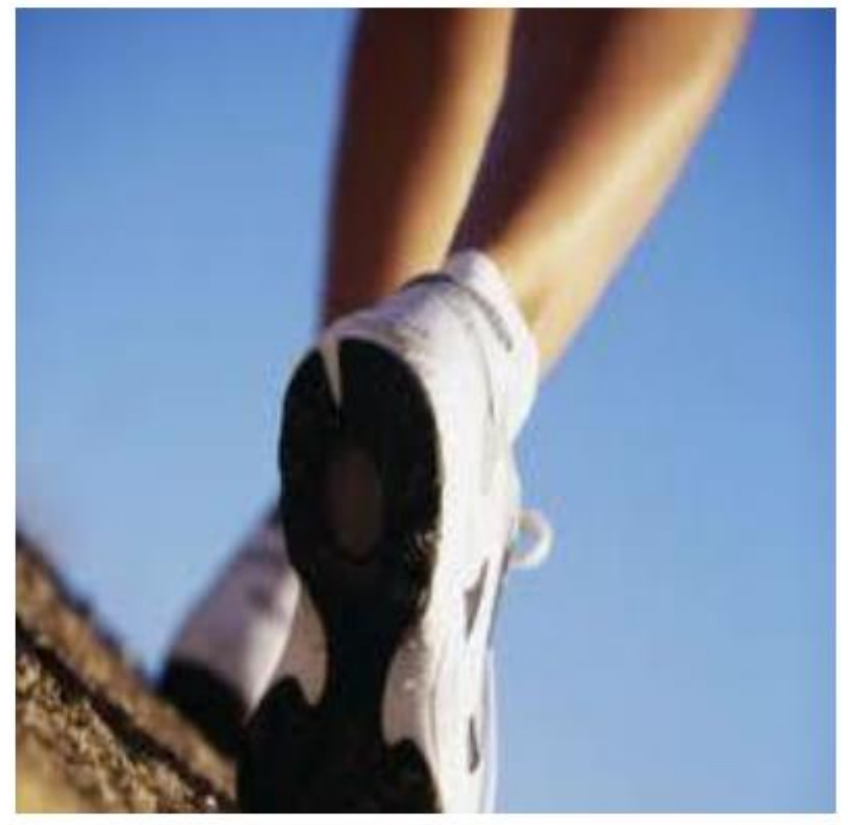


Contents

Page

Introduction

The benefits of physical activity

How much should you do?

6

Taking your first steps

Set yourself goals

9

Listen to your body....stay safe

11

Keeping a record of your wal king

12

Rating intensity/exertion of your walking 


\section{Introduction}

Regardless of your age, health or physical condition most people are likely to benefit from becoming more active. As a society we have become a lot less active with technology and hectic life styles overshadowing the simple things in life such as walking to pick the kids up from school or taking them to the park.

Walking is one of the easiest and most effective ways of gaining a healthier lifestyle: just 30 minutes of walking spread throughout the day will help you to improve your physical fitness and overall quality of life. Furthermore it is easy free and it can be done anywhere at any time either with friends or alone.

This booklet has been produced to provide you with both a practical guide and encouragement to help you take your first steps in the right direction. The aim of the booklet is to help you to develop a personal walking plan guiding you to a healthier lifestyle. When living with cancer, although daunting, physical activity is safe and can help to make a positive change in your life.

This booklet is a guide and should not replace advice provided by health professionals. If at any point you feel unwell please contact your consultant, a breast cancer nurse or your $G P$. 
Benefits of physical activity during cancer treatment

Over the last few years doctors have moved away from advising cancer patients to rest towards encouraging physical activity. It is a common theme within current research that cancer patients should aim to be physically active after surgery and during treatment to enable patients to return to daily activities as soon as possible. Being physically active when living with cancer is safe and has a number of benefits. Research now tell us that keeping active can help improve your physical fitness, enhance psychological well-being, reduce some cancer related side effects and reduce the risk of your cancer coming back.

Physical activity has a number of benefits for improving your lifestyle and minimising some the side effects associated with treatment. Understanding these benefits and knowing what being physically active can do for you may provide you with the motivation to put your intentions into action.

For example, regular activity such as walking can help to:

- Reduce fatigue often experienced by breast cancer patients.

Fatigue is a common side effect of chemotherapy for breast cancer patients and can last for months or years after treatment. Becoming more active can help you to reduce tiredness. Regular moderate intensity physical activity can help to increase energy levels in turn minimising tiredness caused by chemotherapy. 
- Reduce stress and anxiety

Needless to say treatment for cancer can create a number of anxieties. Regular physical activity can help to control for this through the release of chemicals and hormones.

- Improve your confidence and self-esteem

Setting yourself realistic, manageable goals can help you to increase your self-confidence. Setting your own goals and completing them gives you the power to be in control as well as making you feel good.

- Improve low mood and depression

Physical activity, such as brisk walking, releases the happy hormone and also gives you the opportunity to get some fresh air and take advantage of the environment.

Walking may also help to:

- Feel better about yourself

- Help manage your weight

- Increase energy levels

- Improve your sleep

- Enjoy the environment

- Socialise, make new friends or provide an opportunity to meet up with friends. 
Becoming physically active doesn't mean that you need to join a fancy gym or turn your life upside down to accommodate exhausting runs. Regular walking incorporated into your daily routine is all you need to take advantage of the benefits of walking.

Why not try some of the tips below?

- Walk to your local shop instead of taking the car or the bus.

- Make walking part of your social life. Go for a walk with friends instead of going for a coffee or better still walk to the coffee shop.

- Arrange to go for regular walks with family or friends. Walking together will help you to motivate and support one another

- Walking with children/grandchildren can be a fun activity for everyone and you can explore your surroundings together.

Can you think of other ways to incorporate walking into your daily routine? 


\section{How much walking should you do?}

It is recommended that adults take part in at least 2.5 hours of moderate intensity exercise a week to maintain a healthy lifestyle. You may wish to split this into 30 minute sessions five times a week. Alternatively, you may prefer to break your walking down into 10 minutes of activity three times a day, five days of the week. The duration of walking you do in one session should be based upon your own personal preference and abilities. If you are not used to walking or have become less physically active since your diagnosis, begin slowly and gradually build up the duration of time you walk.

Moderate intensity physical activity refers to working hard enough that your body is warming up and your heart is beating faster. You should notice that you are breathing quicker and deeper but not to the point where you are unable to maint ain a conversation. Brisk walking is a good example of moderate intensity activity. You should aim towards walking at moderate intensity for at least 2.5 hours a week. It is recommended that you carry out at least 10 minutes of continuous walking at any one time to take full advantage of its benefits. Regular sessions of moderate intensity activity are far more beneficial than small bouts of vigorous intensity exercise. 


\section{Taking your first steps}

Whether you are becoming physically active for the first time or you are trying to resume activity after your diagnosis, it is not going to be an easy journey. Knowing the benefits of being more active, setting manageable goals and remaining motivated will help you take your first steps towards a healthier lifestyle.

- Why do you want to be more active?

Knowing why you want to become more active and setting yourself goals will help you to stay motivated whilst walking towards a healthier lifestyle.

The questions below may help you to get started.

1. What are your top three reasons for becoming physically active? For example, 'Being more active will help me feel more confident' or 'walking more will help me manage my weight'.

a) 
b)

2. Please complete the following statement. 'Walking more would make me feel

3. How would being physically active alter your life? For example, 'Walking more will help me build up my strength and allow me to spend more time with the children/grandchildren'. 
4. If you decide not to become more physically active, how do you think this will affect your life? For example, 'I may not have the energy to return to work' or 'I would be stuck indoors'.

\section{Set yourself goals}

Knowing what you are working towards and why will make it easier for you to take those first steps. The first few steps that you take are the most important, so set yourself small achievable goals. If you are not used to walking or have not done so for a while, start slow and gradually build it up. If you feel that you are unable to walk at moderate intensity for 30 minutes begin by walking for $5 / 10$ minutes and gradually build this up as you become more comfortable and your body begins to adjust. 
These initial $5 / 10$ minutes of walking can easily be incorporated into your daily routine. For example,

- if you are going shopping park your car a little further away from the shops or get off the bus a couple of stops earlier and walk the rest of the way.

-walk to pick the children/grandchildren up from school instead or driving

-avoid using the escalators or lift and take advantage of the stairs instead

As you become more comfortable walking you can slowly begin to build up the intensity and duration of each walk. Begin by adding a couple of minutes on to each walk and picking up the pace. It is important that you set realistic goals, if you aim too high you may not reach your goal which will leave you feeling disheartened. As you become more comfortable you will be able to set higher goals. It is recommended that you aim to walk for at least 30 minutes a day, in bouts of 10 minutes five times a week.

For example, if you begin by walking for 5 minutes at a time, as you become more comfortable you may wish to increase this to 7 minutes of moderate intensity walking. Therefore, you would be walking for bouts of 7 minutes at least 4 times a day. You can set daily goals in your activity diary. 
Listen to your body.....and stay safe.

It is important that you listen to your body at every stage and slow down if you feel you begin to feel unwell.

-Do not exercise if you are feeling unwell.

-If at any stage you feel that walking is making you dizzy, you feel pain, discomfort or dizzy you should stop exercising and contact your GP, consultant or breast cancer nurse immediately.

- Ensure you have the correct footwear. Your shoes should be comfortable and supportive.

- As you become more comfortable and confident you may begin to go for longer walks. In this case you should begin slowly to enable your muscles to warm up and gradually build up. Similarly you should gradually slow down towards the end of the walk.

-It is very important to keep yourself hydrated during treatment so remember to drink plenty of water before, during and after exercising. -Eat healthily before and after exercising. You should aim to eat carbohydrates before exercising and a healthy snack afterwards. -You should al ways walk in well-lit areas where it is busy. Never make yourself vulnerable by walking alone in dark desolate areas.

-Carry a mobile phone with you in case of emergencies. -When walking alone, always tell somebody where you are going and approximately how long you intend to be out walking. 


\section{Keeping a record of your walking}

After you have set your goals and have supportive footwear you will be ready to start walking. Keeping a record of the amount of walking you do will help you to see how you are progressing and reflect upon your goals and achievements through the 12 week programme.

We have provided you with a pedometer to enable you to monitor your steps and help you reach your goals. A pedometer is a device that can be attached to your waist and will calculate the number of steps you take each day and can be reset at the end of each day. To reach the recommended 30 minutes of exercise you should be aiming to reach 10,000 steps per day. This may not be possible in the first couple of weeks, but if you remind yourself of the benefits of walking, set yourself goals and do your best to reach them you will be surprised at how much your step count has increased by week 12 .

It will be useful to recall the average number of steps you took a day whilst you wore the accelerometer at the beginning of the research. (If you are unsure, ask the researcher as she will have a record of this). Knowing your baseline step count will enable you to set yourself realistic goals. Remember, if you are unable to reach your goals or fell unwell, do not be disheartened. Think about why you were unable to reach your goal and make another one. 
We have provided you with an activity diary in which we would like you to record the number of steps taken and the intensity of your walking on a daily basis. The number of steps is simply a record of the number of steps displayed on the pedometer at the end of each day. The intensity of your walking can be measured using the scale on the back page of the activity diary or by using The Talk Test.

The Talk Test is a simple way in which you can monitor the intensity of your walking whilst you are exercising. Walking at moderate intensity levels, you should still be able to maintain a conversation but not be able to sing as this would make you feel breathless. If you are walking at vigorous intensity levels you will be unable to speak more than a couple of words. Remember, you should be aiming to walk at moderate levels of intensity.

Another simple way to measure use walking intensity is using the scale on the back page of this booklet. The scale requires you to rate how hard you feel your body is working based on the physical sensations you experience including increased heart rate, breathing rate and sweating. If you refer to the scale, you will see that exertion is measured on a rating scale with ' 6 ' indicating 'no exertion at all' and '20' indicating 'maximal exertion'. Moderate intensity exercise is rated between 12 and 14 on the scale. Although you are aiming to exercise 
at a moderate intensity, you may find that you are exercising higher or lower on the scale based upon your personal abilities and condition.

During treatment it is likely that you will have some good days during which you will be able to reach and in some cases exceed your goals. However, there may also be days when you are feeling to unwell to exercise. This is to be expected whilst receiving treatment and you should bare this in mind whilst setting your goals. 


\section{Rating the intensity/exertion of your walking}

Use the scale below to rate the intensity of your walking. While doing physical activity, we want you to rate your perception of exertion. This feeling should reflect how heavy and strenuous the exercise feels to you, combining all sensations and feelings of physical stress, effort, and fatigue. Do not concern yourself with any one factor such as leg pain or shortness of breath, but try to focus on your total feeling of exertion.

Look at the rating scale below while you are engaging in an activity; it ranges from 6 to 20, where 6 means "no exertion at all" and 20 means "maximal exertion." Choose the number from below that best describes your level of exertion. This will give you a good idea of the intensity level of your activity, and you can use this information to speed up or slow down your movements to reach your desired range.

Try to appraise your feeling of exertion as honestly as possible, without thinking about what the actual physical load is. Your own feeling of effort and exertion is important, not how it compares to other people. Look at the scales and the expressions and then give a number. 


\begin{tabular}{|c|c|c|}
\hline $\begin{array}{l}\text { How you might describe } \\
\text { your exertion }\end{array}$ & $\begin{array}{l}\text { Rating your } \\
\text { exertion }\end{array}$ & Examples \\
\hline None & 6 & Reading a book, watching television \\
\hline Very, very light & 7 to 8 & Tying shoes \\
\hline Very light & 9 to 10 & $\begin{array}{l}\text { Chores like folding clothes that seem to take } \\
\text { little effort }\end{array}$ \\
\hline Fairly light & 11 to 12 & $\begin{array}{l}\text { Walking through the grocery store or other } \\
\text { activities that require some effort but not enough } \\
\text { to speed up your breathing }\end{array}$ \\
\hline Somewhat hard & 13 to 14 & $\begin{array}{l}\text { Brisk walking or other activities that require } \\
\text { moderate effort and speed your heart rate and } \\
\text { breathing but don't make you out of breath }\end{array}$ \\
\hline Hard & 15 to 16 & $\begin{array}{l}\text { Bicycling, swimming, or other activities that take } \\
\text { vigorous effort and get the heart pounding and } \\
\text { make breathing very fast }\end{array}$ \\
\hline Very hard & 17 to 18 & The highest level of activity you can sustain \\
\hline Very, very hard & 19 to 20 & $\begin{array}{l}\text { A finishing kick in a race or other burst of activity } \\
\text { that you can't maintain for long }\end{array}$ \\
\hline
\end{tabular}

If you have any questions at any point during or after the 12 week walking programme please do not hesitate in contacting Kajal Gokal (researcher) at Loughborough University: Tel: 01509228152 E-mail: K.Gokal@lboro.ac.uk

This booklet was designed based upon previous literature and other walking intervention booklets developed by Macmillan Cancer Support (Move More) and The British Heart Foundation (Put Your Heart into Walking). 